\title{
Is Chest Compression Superimposed with Sustained Inflation during Cardiopulmonary Resuscitation an Alternative to 3:1 Compression to Ventilation Ratio in Newborn Infants?
}

\author{
Seung Yeon Kim ${ }^{1,2,+}$, Gyu-Hong Shim ${ }^{1,3,+} \mathbb{i}$ and Georg M. Schmölzer ${ }^{1,4,5, * \mathbb{C}}$ \\ 1 Centre for the Studies of Asphyxia and Resuscitation, Neonatal Research Unit, Royal Alexandra Hospital, \\ Edmonton, AB T5H 3V9, Canada; dunggiduk@eulji.ac.kr (S.Y.K.); peddoc@paik.ac.kr (G.-H.S.) \\ 2 Department of Pediatrics, Eulji University Hospital, Daejeon 35233, Korea \\ 3 Department of Pediatrics, Inje University Sanggye Paik Hospital, Seoul 01757, Korea \\ 4 Department of Pediatrics, Faculty of Medicine and Dentistry, University of Alberta, \\ Edmonton, AB T6G 2R3, Canada \\ 5 Division of Neonatology, Department of Pediatrics and Adolescent Medicine, Medical University of Graz, \\ Graz 8036, Austria \\ * Correspondence: georg.schmoelzer@me.com; Tel.: +1-78-0735-5179; Fax: +1-78-0735-4072 \\ + These authors contributed equally to this work.
}

Citation: Kim, S.Y.; Shim, G.-H.;

Schmölzer, G.M. Is Chest Compression Superimposed with Sustained Inflation during Cardiopulmonary Resuscitation an Alternative to 3:1 Compression to Ventilation Ratio in Newborn Infants? Children 2021, 8, 97. https://doi.org/ $10.3390 /$ children8020097

Academic Editor: Waldemar A. Carlo Received: 29 December 2020

Accepted: 29 January 2021

Published: 2 February 2021

Publisher's Note: MDPI stays neutral with regard to jurisdictional claims in published maps and institutional affiliations.

Copyright: (c) 2021 by the authors. Licensee MDPI, Basel, Switzerland. This article is an open access article distributed under the terms and conditions of the Creative Commons Attribution (CC BY) license (https:// creativecommons.org/licenses/by/ $4.0 /)$.

\begin{abstract}
Approximately $0.1 \%$ for term and $10-15 \%$ of preterm infants receive chest compression (CC) in the delivery room, with high incidence of mortality and neurologic impairment. The poor prognosis associated with receiving CC in the delivery room has raised concerns as to whether specificallytailored cardiopulmonary resuscitation methods are needed. The current neonatal resuscitation guidelines recommend a 3:1 compression:ventilation ratio; however, the most effective approach to deliver chest compression is unknown. We recently demonstrated that providing continuous chest compression superimposed with a high distending pressure or sustained inflation significantly reduced time to return of spontaneous circulation and mortality while improving respiratory and cardiovascular parameters in asphyxiated piglet and newborn infants. This review summarizes the current available evidence of continuous chest compression superimposed with a sustained inflation.
\end{abstract}

Keywords: newborn; neonatal resuscitation; chest compressions; sustained inflation

\section{Introduction}

Approximately $0.1 \%$ of term infants and $10-15 \%$ of preterm infants receive chest compressions (CC) in the delivery room (DR) [1-5]. Infants who receive CC have a high incidence of mortality and neurodevelopmental impairment [1-5]. Furthermore, newborns who received prolonged CC and epinephrine without signs of life at $10 \mathrm{~min}$ after birth have $83 \%$ mortality, with $93 \%$ of survivors suffering moderate-to-severe neurological disability [6,7]. The poor prognosis associated with receiving CC in the DR has raised concerns as to whether specifically-tailored cardiopulmonary resuscitation (CPR) methods could improve outcomes.

In newborn infants, bradycardia or cardiac arrest is mainly caused by hypoxia rather than a primary cardiac disease $[8,9]$. Therefore, the neonatal resuscitation guidelines put an emphasis on ventilation and adequate oxygen delivery. Current neonatal resuscitation guidelines recommend initiating CC if an infant's heart rate remains $<60$ beats $/ \mathrm{min}$, despite adequate ventilation for at least $30 \mathrm{~s}[8,9]$. CC should be delivered at a rate of $90 / \mathrm{min}$ in sequences of three CC followed by a pause to deliver 1 inflation at a rate of $30 /$ min, which corresponds to a 3:1 compression:ventilation $(\mathrm{C}: \mathrm{V})$ ratio $[8,9]$. The $3: 1 \mathrm{C}: \mathrm{V}$ ratio is recommended, as respiratory failure is the primary cause of bradycardia or asystole in newborn infants [8,9]. A 3:1 C:V ratio has a higher rate of inflations compared to the pediatric or adult $C: V$ ratios, which will result in a higher oxygen delivery, hence improved 
ventilation [8,9]. While the current neonatal resuscitation guidelines recommend a 3:1 C:V ratio, the most effective $\mathrm{C}: \mathrm{V}$ ratio in newborn infants remains controversial.

Several studies have compared various $\mathrm{C}: \mathrm{V}$ ratios or continuous chest compression with asynchronized ventilation [10-14], however none of the studies reported any improved outcomes compared to the 3:1 C:V ratio. More recently, our group used a higher airway pressure or sustained inflation during continuous chest compression $(\mathrm{CC}+\mathrm{SI})$, which significantly improved time to return of spontaneous circulation (ROSC) and survival [15]. While the current available data is mostly limited to animal data, some human data are available. The aim of the review is to provide an in-depth analysis of CC + SI during neonatal CPR.

\section{3:1 Compression-to-Ventilation Ratio: Rationale and Evidence}

Current resuscitation guidelines in newborns recommend a 3:1 C:V ratio $[8,9]$, however this approach may not be optimizing coronary and cerebral perfusion while providing adequate ventilation to improve outcomes. Animal studies on cardiac arrest demonstrated that combining CC with ventilations, compared with ventilations or CC alone, improves ROSC and neurological outcome at $24 \mathrm{~h}$ in asphyxiated newborn piglets [16-18].

Solevåg et al. compared 9:3 C:V and 15:2 C:V to 3:1 C:V in asphyxiated newborn piglets with cardiac arrest and reported no significant differences in the time to ROSC $[10,11]$. These studies suggest that just using a higher $\mathrm{C}: \mathrm{V}$ ratio does not improve outcome in asphyxiated newborn piglets. Alternatively, continuous $C C$ with asynchronous ventilations (CCaV), where $90 \mathrm{CC}$ are given continuously with 30 non-synchronized inflations, would potentially improve hemodynamics during CC as there are no interruptions. Indeed, a manikin study reported a significantly higher minute ventilation with $\mathrm{CCaV}$ compared to 3:1 C:V ratio (221 vs. $191 \mathrm{~mL} / \mathrm{kg} / \mathrm{min}$, respectively) [19]. During CPR in asphyxiated newborn piglets, $\mathrm{CCaV}$ or $3: 1 \mathrm{C}: \mathrm{V}$ had similar minute ventilation $(387 \mathrm{vs} .275 \mathrm{~mL} / \mathrm{kg}$ ) and similar time to ROSC (114 and $143 \mathrm{~s}$ for CCaV and 3:1 C:V, respectively) and survival $(3 / 8$ and $6 / 8$, respectively) between the two groups $[12,13]$. Furthermore, no differences in diastolic blood pressure or mean arterial blood pressure between $\mathrm{CCaV}$ and 3:1 C:V were observed $[12,13]$. These studies suggest that $\mathrm{CCaV}$ has no advantage compared to 3:1 C:V.

\section{Chest Compression with Sustained Inflations (CC + SI)}

Schmölzer et al. compared continuous CC superimposed with a high distending pressure (or sustained inflation $=\mathrm{CC}+\mathrm{SI}$ ) with 3:1 CV during CPR of asphyxiated newborn piglets and reported (i) significantly reduced time to ROSC (median (Interquartile range (IQR)) $38(23-44)$ vs. $143(84-303) \mathrm{s}$, respectively, $(p=0.0008)$, mortality $(7 / 8(87.5 \%)$ vs. $3 / 8(37.5 \%)$, respectively, $p=0.038)$, epinephrine administration $(0 / 8 \mathrm{vs} .7 / 8$, respectively, $p<0.0001$ ), and improved systemic and regional hemodynamic recovery; (ii) less infants received $100 \%$ oxygen ( $3 / 8$ vs. $8 / 8$, respectively, ( $p=0.0042$ ); (iii) minute ventilation (mean (SD) 936 (201) vs. $623(116) \mathrm{mL} / \mathrm{kg} / \mathrm{min}$, respectively, $p=0.0080)$, and therefore alveolar oxygen delivery, was significantly increased with CC + SI; iv) compression of the chest during SI forced gas out of the chest and during passive chest recoil allowed air to be drawn back into the lungs [15].

During CC + SI, CCs are delivered continuously and superimposed by a constant high airway pressure or sustained inflation (SI). During CC + SI, a constant high airway pressure or $\mathrm{SI}$ is given for a set time (e.g., $30 \mathrm{~s}$ ) with a set peak inflation pressure (e.g., $25 \mathrm{~cm} \mathrm{H}_{2} \mathrm{O}$ ) while CCs are continuously delivered [20-24]. During compression and release phase, the distending pressure is fluctuating by $\sim \mathrm{cm} \mathrm{H}_{2} \mathrm{O}$. After the set time (i.e., $30 \mathrm{~s}$ ), the $\mathrm{SI}$ is paused for $1 \mathrm{~s}$ while CCs are continued. The SI is then resumed for the same time frame (i.e., 30 s). Both CC and SI combined as CC + SI are continued until ROSC. While in all studies a $1 \mathrm{~s}$ pause between each SI was used, the optimal duration for the pause between each SI (e.g., 0.5, 1, $2 \mathrm{~s}$ ) has never been examined. 


\section{Mechanism of CC + SI}

Antegrade blood flow during CPR can be achieved by either direct cardiac compression between the sternum and vertebral column or increased intrathoracic pressure produced by CC [25]. Indeed, maneuvers that increase the intrathoracic pressure result in increased carotid blood flow during CPR, further augmenting antegrade blood flow $[26,27]$. Chandra et al. combined ventilation at high airway pressure while simultaneously performing CC in an animal model and demonstrated increased carotid flow, without compromising oxygenation $[26,27]$. Furthermore, providing continuous CC and lung inflation simultaneously substantially improved brain perfusion by enhancing cerebral perfusion pressure in a piglet model [28,29]. In addition, animal studies have demonstrated that an SI also increases intrathoracic pressure without impeding blood flow [30]. These data suggest that CC + SI might provide two maneuvers, which increase intrathoracic pressure and thereby improve blood flow.

\section{Chest Compression Rate}

The newborn infant normal respiratory rate and resting heart rate are $40-60$ breaths $/ \mathrm{min}$ and $120-160 / \mathrm{min}$, respectively. In comparison, the current neonatal resuscitation guidelines recommend CC with 90 compressions and 30 inflations per minute [8,9], which is lower than the normal physiological parameters.

Schmölzer et al. compared CC + SI with a CC rate of $120 / \mathrm{min}$ with 3:1 C:V with a CC rate of $90 / \mathrm{min}$ in a newborn asphyxiated piglets experiment, and reported shorter time to ROSC (38 (23-44) vs. $143(84-303) \mathrm{s} ;(p=0.0008))$ and survival to $4 \mathrm{~h}$ with $7 / 8$ vs. $3 / 8$, respectively [15]. Similarly, Vali et al. reported that CC + SI with CC rate of $120 / \mathrm{min}$ was as effective as CC with 90/min with a 3:1 C:V ratio in achieving ROSC [31]. Li et al. compared CC rates of $90 / \mathrm{min}$ and $120 / \mathrm{min}$ during CC + SI and reported a reduced time to ROSC (34 (28-156) vs. 99 (31-255) s $p=0.29$ ), respectively [32]. Those studies suggest the $90 / \mathrm{min}$ CC rates in the CC + SI might be sufficient to deliver an adequate tidal volume and minute ventilation without impairing gas exchange. However, a mathematical model suggests that the most effective CC rate depends on body size and body weight, and CC rates of $180 / \mathrm{min}$ for term infants and even higher for preterm infants might improve survival [33]. The mathematical model calculated that the optimal systemic perfusion pressure occurs at CC rates of 180 and $250 / \mathrm{min}$ for infants weighing 3 and $1 \mathrm{~kg}$, respectively [33]. In infants and newborns, there are fundamental physical and mathematical reasons including (i) effects of the mass of venous blood columns entering the chest pump, (ii) length, and (iii) area scale with body size [33]. However, these higher CC rates might be impossible during manual $\mathrm{CPR}$ as healthcare professionals will get fatigued more quickly, which conversely affects CC quality [34-36]. Using an automated CC machine might be the solution to achieving these high CC rates. While automated CC machines are routinely used in adults, no such device is currently available for newborn infants.

\section{Peak Inflation Pressures}

The optimal peak inflation pressure during CC + SI for adequate tidal volume delivery is unknown. While the current neonatal resuscitation guidelines recommend an initial distending pressure of $20-25 \mathrm{~cm} \mathrm{H}_{2} \mathrm{O}$ during positive pressure ventilation [8,9], the optimal peak inflation pressure remains unknown. During mask ventilation, a certain threshold peak inflation pressure is needed to move the liquid air interface downwards towards the alveoli $[37,38]$. Similarly, during CC + SI, a threshold sustained pressure is needed to deliver an adequate tidal volume. Solevåg et al. used manikins and cadaver piglets to establish the distending pressure required to achieve sufficient tidal volume delivery during CC + SI [39]. A distending pressure of $25 \mathrm{~cm} \mathrm{H}_{2} \mathrm{O}$ was required to achieve a tidal volume delivery of $>5 \mathrm{~mL} / \mathrm{kg}$ [39]. Tidal volume increased with increasing distending pressure in all models, with an overall positive correlation $(r=0.49, p<0.001)$ [39]. Shim et al. compared a peak inflation pressure of 10,20 , and $30 \mathrm{~cm} \mathrm{H}_{2} \mathrm{O}$ during $\mathrm{CC}+\mathrm{SI}$ in asphyxiated newborn piglets and reported no difference in median (IQR) time to ROSC, 
with 75 (63-193), 94 (78-210), and 85 (70-90) s, respectively ( $p=0.56)$ [22]. In addition, tidal volume was positively correlated with increasing pressure with a mean (SD) 7.3 (3.3), 10.3 (3.1), and 14.0 (3.3) $\mathrm{mL} / \mathrm{kg}$; $(p=0.0018)$ with 10,20 , and $30 \mathrm{~cm} \mathrm{H}_{2} \mathrm{O}$, respectively [22]. The higher tidal volume with a peak inflation pressure of $30 \mathrm{~cm} \mathrm{H}_{2} \mathrm{O}$ also showed increased concentrations of proinflammatory cytokines interleukin- $1 \beta$ and tumor necrosis factor- $\alpha$ in the frontoparietal cerebral cortex (both $p<0.05$ vs. sham-operated controls). These data suggest that pressures of $20-25 \mathrm{~cm} \mathrm{H}_{2} \mathrm{O}$ might be sufficient to deliver an adequate tidal volume during CC + SI, and that higher pressures could lead to increases in lung inflammation markers.

\section{Passive Ventilation}

Tsui et al. applied a downward force of $0.16 \mathrm{~kg}$ per $\mathrm{kg}$ patient weight on the chest of infants undergoing surgery during general anesthesia and was able to deliver a tidal volume of $2.4 \mathrm{~mL} / \mathrm{kg}$ or $\sim 33 \%$ of an infant's physiological tidal volume [40]. This study suggests that chest recoil produces a distending pressure-dependent tidal volume, which achieves passive ventilation during CCs. In asphyxiated term piglets, the delivered tidal volume was $10-15 \mathrm{~mL} / \mathrm{kg}$ with a constant distending pressure of $25-30 \mathrm{~cm} \mathrm{H}_{2} \mathrm{O}$, and in preterm infants $<32$ weeks' gestation, the tidal volume ranged between 0.6 to $4.4 \mathrm{~mL} / \mathrm{kg}$ with a constant distending pressure of $24 \mathrm{~cm} \mathrm{H}_{2} \mathrm{O}[15,41]$. These data demonstrate that passive ventilation is achieved when providing a constant high distending pressure during CC.

\section{Tidal Volume}

Providing adequate ventilation is a cornerstone of neonatal CPR. The main purpose of lung inflations during CCs is to provide an adequate tidal volume to facilitate oxygen delivery and gas exchange. However, during CPR with $3: 1 \mathrm{C}: \mathrm{V}, \mathrm{Li}$ et al. reported a cumulative loss of expiratory tidal volume of $4.5 \mathrm{~mL} / \mathrm{kg}$ with each $3: 1 \mathrm{C}: \mathrm{V}$ cycle [42], which could cause lung derecruitment and thereby interfere with oxygenation and ROSC. In comparison, during CC + SI, a constant lung recruitment and thereby gain in functional residual capacity was observed with a tidal volume gain of $2.4 \mathrm{~mL} / \mathrm{kg}$ per CC + SI cycle [42]. This is supported by data from a human pilot trial comparing CC + SI with 3:1 $\mathrm{C}: \mathrm{V}$ in the DR using a distending pressure of $24 \mathrm{~cm} \mathrm{H}_{2} \mathrm{O}$ (local hospital policy during neonatal resuscitation) in preterm infants $<32$ weeks of gestation [41,43]. During CC + SI, a significantly higher tidal volume and minute ventilation was delivered, suggesting that $\mathrm{CC}+$ SI might improve ventilation and oxygenation during neonatal CPR. During CC + SI, adequate tidal volume delivery might lead to better alveolar oxygen delivery and lung aeration, hence faster ROSC compared to 3:1 C:V group.

\section{Duration of Sustained Inflations}

SI as initial respiratory support in the DR has been postulated to achieve a more unified lung aeration [44]. However, recent systematic reviews reported similar rates of bronchopulmonary dysplasia when SI was compared with intermittent positive pressure ventilation for initial respiratory support in the DR $[45,46]$. These reviews also reported that in a subgroup of $<28$ weeks' gestation, SI was associated with potential increased risk of death before discharge (risk ratio $2.42(95 \%$ confidence interval $=1.15-5.09)$ ) and increased risk of death within the first 2 days (risk ratio 1.38 (95\% confidence interval = 1.00-1.91)), when compared to intermittent positive pressure ventilation $[45,46]$. However, the mechanism of how an initial SI could potentially increase risk of death is unknown.

Furthermore, the European resuscitation guidelines recommend five SIs of $3 \mathrm{~s}$ in asphyxiated term infants [47], though no human studies have examined this approach in newborn infants. However, a recent study in asphyxiated lambs reported that a $30 \mathrm{~s}$ SI will achieve lung aeration and hemodynamic stability, while five SIs of 3 s does not [48]. In the original study, we used a 30 s SI during CC + SI, which significantly reduces time to ROSC compared to 3:1 C:V ratio [15]. However, the optimal duration of SI to improve ROSC and reduce mortality during CC + SI remains unknown. Mustofa et al. compared CC + SI with 
either $20 \mathrm{~s}$ or $60 \mathrm{~s}$ in asphyxiated piglets and reported similar time to ROSC and survival, with no difference in tidal volume delivery [21]. In addition, there were no differences in markers of lung inflammation (IL-1ß, IL-6, IL-8, and TNF- $\alpha$ ) and brain inflammation (IL-1B, IL-6, and IL-8) between the groups [21]. This suggests that the duration of SI during $\mathrm{CC}+\mathrm{SI}$ might be not the dependent factor, however further studies are needed to identify the optimal duration of SI during CC + SI.

\section{Oxygen Concentration with CC + SI}

The current neonatal resuscitation guidelines recommend $100 \%$ oxygen once CCs are initiated [8,9]. However, this is based on expert opinions and not supported by any clinical data. Several animal studies compared $21 \%$ or $100 \%$ oxygen during CC using the 3:1 C:V ratio in asphyxiated newborn piglets and reported no difference in time to ROSC or mortality. In addition, the cumulative alveolar oxygen exposure during resuscitation was significantly lower in the CC + SI group compared to the 3:1 C:V group, with mean (SD) $27,755$ (4706) and 47,729 (6692) $\mathrm{mmHg}$ seconds, respectively ( $p<0.001)$. Similar, a metaanalysis of these animal studies reported no difference in time to ROSC (mean difference of $-3.8(-29.7-22) \mathrm{s}, \mathrm{I}^{2}=0 \%, p=0.77$ ) or mortality (risk ratio $1.04(0.35,3.08), \mathrm{I}^{2}=0 \%, p=0.94$ ) between $21 \%$ or $100 \%$ oxygen during CC with the $3: 1 \mathrm{C}: \mathrm{V}$ ratio [49]. Recently, Hidalgo et al. compared $21 \%$ and $100 \%$ oxygen during CC + SI in term newborn asphyxiated piglets and reported similar time to ROSC (median (IQR) 80 (70-190) vs. 90 (70-324) s, respectively, $p=0.56)$, short-term survival $(7 / 8(88 \%)$ vs. $5 / 8(63 \%)$, respectively, $p=0.569)$, and hemodynamic recovery [50]. In addition, there was no significant difference in injury markers in the left ventricle tissue or the frontoparietal cortex tissue. These data suggest that $21 \%$ oxygen during CPR might be efficient, however human data are needed.

\section{Type of Cardiac Arrest}

In 2015, the neonatal resuscitation guidelines added the use of an electrocardiograph to assess heart rate at birth [51,52]. This led to several reports of pulseless electrical activity during CPR in the DR $[53,54]$. In addition, rates of up to $50 \%$ of asphyxiated piglets displayed pulseless electrical activity during asphyxia-induced cardiac arrest [55-57]. Solevåg et al. reported that cardiac arrest due to pulseless electrical activity will result in lower rates of ROSC and lower $4 \mathrm{~h}$ survival, compared to asystole, in asphyxiated newborn piglets [56]. This suggests that the initial electrocardiograph algorithm might serve as an outcome predictor during neonatal CPR.

\section{Inflammatory Markers}

There are concerns that SI could adversely affect lung or brain injury. Lista et al. reported a pneumothorax rate of $6 \%$ compared to $1 \%$ with intermittent positive pressure in preterm infants with 25-28 weeks of gestation [58]. However, the mechanisms for an increased rate of pneumothorax during SI is unknown. Interestingly, none of the animal studies examining CC + SI reported pneumothoraxes during autopsy. There is also the concern that SI delivers an excessive large tidal volume, which could cause a pulmonary proinflammatory response and initiate systemic inflammatory cascade [59]. However, when SIs were given as initial respiratory support, no increase in lung injury marker has been reported [60,61]. Similar, during CPR with either CC + SI or 3:1 C:V, no difference in lung injury markers were observed.

The mechanism of brain injury is thought to be impaired venous return or secondary brain injury due to excessive tidal volume delivery. Sobotka et al. reported that a single $30 \mathrm{~s}$ SI followed by ventilation caused a blood-brain barrier disruption and cerebral vascular leakage, which may exacerbate brain injury in asphyxiated near-term lambs [62]. This injury might have occurred as a direct insult of the initial SI or due to the excessive tidal volume delivered during subsequent ventilation. Recently, Shim et al. reported that a peak inflation pressure of $30 \mathrm{~cm} \mathrm{H} \mathrm{H}_{2} \mathrm{O}$ delivered a significant higher tidal volume compared to peak inflation pressure of $20 \mathrm{~cm} \mathrm{H}_{2} \mathrm{O}$, which was associated with significant increased 
cerebral tissue pro-inflammatory cytokines [22]. While CC + SI did not increase lung injury markers, markers of brain inflammation were increased, and therefore a peak inflation pressure of $\geq 25 \mathrm{~cm} \mathrm{H}_{2} \mathrm{O}$ should not be exceeded.

\section{Clinical Studies}

The animal data suggest that CC + SI might be an effective CC technique for newborn infants. A pilot trial compared CC + SI $(n=5)$ with $3: 1 \mathrm{C}: \mathrm{V}(n=4)$ in preterm infants $<32$ weeks' gestation with a mean (SD) gestational age of 24.6 (1.3) and 25.6 (2.3) weeks [41]. There was a significantly shorter time to ROSC with CC + SI, compared to 3:1 $\mathrm{C}: \mathrm{V}$, with 31(9) vs. $138(72) \mathrm{s}$, respectively ( $p=0.011)$ [41]. In addition, CC + SI provided a higher minute ventilation and ventilation rate, while short-term outcomes, including intraventricular hemorrhages, air leak, retinopathy of prematurity, and chronic lung disease, were similar between groups [41]. Although mortality was higher in the CC + SI group with $2 / 5$ vs. $0 / 4$ in the $3: 1 \mathrm{C}: \mathrm{V}$ group, this did not reach statistical significance, as the sample size was too small, and it was a very vulnerable patient population.

Currently, the Sustained Inflation and Chest Compression Versus 3:1 Chest Compression to Ventilation Ratio During Cardiopulmonary Resuscitation of Asphyxiated Newborns: A Randomized Controlled Trial (SURV1VE-trial) is recruiting term and preterm infants born $>28^{+0}$ weeks' gestational age requiring chest compression in the delivery room $[63,64]$. In this cluster trial, hospitals are randomized to either $\mathrm{CC}+\mathrm{SI}$ or $3: 1 \mathrm{C}: \mathrm{V}$ ratio for one year each $[63,64]$. The SURV1VE-trial has been approved by a human clinical research ethical committee at all participating sites, and a Data Safety Monitoring Committee is assessing the results of the trial at regular intervals to assure safety. The SURV1VE-trial hypothesis is that in newborn infants, $\mathrm{CC}+\mathrm{SI}$, compared to $3: 1 \mathrm{C}: \mathrm{V}$, during $\mathrm{CPR}$ will reduce the time needed to ROSC, and aims to recruit 218 participants (109 control group and 109 intervention group). The SURV1VE-trial aims to be completed by 2024.

\section{Limitations}

There are several limitations which prevent routine use of CC $+\mathrm{SI}$ in the DR. Most animal studies described in this review used piglets that have already undergone the fetalto-neonatal transition. All experimental animals were sedated/anesthetized and intubated with a tightly sealed endotracheal tube to prevent any endotracheal tube leak, which may not occur in the delivery room as mask ventilation is frequently used [65].

Furthermore, sustained lung inflations have been postulated as a ventilation strategy immediately after birth [44]. Indeed, in intubated and sedated animals, SI improved lung aeration compared to intermittent positive pressure ventilation. However, several smaller randomized trials and meta-analyses were unable to identify any advantage or disadvantage for either SI or intermittent positive pressure ventilation [66]. Recently, the SAIL trial compared SI with intermittent positive pressure ventilation in $<28$ weeks gestation infants and reported an increased mortality within the first $48 \mathrm{~h}$ with SI [67]. Most recently, a meta-analysis from ILCOR raised concerns about the potential harm of SI for premature infants $<28$ weeks' gestation [46]. These data raise some concerns about the use of SI during the initial respiratory support.

\section{Conclusions}

$\mathrm{CC}+\mathrm{SI}$ reduces time to ROSC, improves mortality, and improves respiratory and hemodynamic parameters compared to $3: 1 \mathrm{C}: \mathrm{V}$ ratio during neonatal CPR. CC + SI allows for passive lung ventilation and adequate tidal volume. Peak inflation pressures of 20-25 cm $\mathrm{H}_{2} \mathrm{O}$ might be sufficient to deliver an adequate tidal volume during $\mathrm{CC}+\mathrm{SI}$, and higher pressures could lead to increases in lung inflammation markers. Furthermore, $21 \%$ oxygen had similar time to ROSC or mortality compared to $100 \%$ oxygen. However, more clinical data are needed before this can be routinely used in the delivery room during neonatal chest compression. 
Author Contributions: Conception and design: S.Y.K., G.-H.S., and G.M.S. Collection and assembly of data: S.Y.K., G.-H.S., and G.M.S. Analysis and interpretation of the data: S.Y.K., G.-H.S., and G.M.S. Drafting of the article: S.Y.K., G.-H.S., and G.M.S. Critical revision of the article for important intellectual content: S.Y.K., G.-H.S., and G.M.S. Final approval of the article: S.Y.K., G.-H.S., and G.M.S. All authors have read and agreed to the published version of the manuscript.

Funding: We would like to thank the public for donating money to our funding agencies: GMS is a recipient of the Heart and Stroke Foundation/University of Alberta Professorship of Neonatal Resuscitation, a National New Investigator of the Heart and Stroke Foundation Canada and an Alberta New Investigator of the Heart and Stroke Foundation Alberta.

Institutional Review Board Statement: Not applicable.

Informed Consent Statement: Not applicable.

Data Availability Statement: All data are presented within the article.

Conflicts of Interest: The authors declare no conflict of interest.

$\begin{array}{ll}\text { Abbreviations } \\ \text { CC } & \text { chest compression } \\ \text { DR } & \text { delivery room } \\ \text { CPR } & \text { cardiopulmonary resuscitation } \\ \mathrm{C}: \mathrm{V} & \text { compression:ventilation } \\ \mathrm{SI} & \text { sustained inflation } \\ \mathrm{CC}+\mathrm{SI} & \text { sustained inflation during chest compression } \\ \text { ROSC } & \text { return of spontaneous circulation } \\ \mathrm{CCaV} & \text { continuous CC with asynchronous ventilations }\end{array}$

\section{References}

1. Shah, P.S.; Shah, P.; Tai, K.F.Y.; Tai, K.F.Y. Chest compression and/or epinephrine at birth for preterm infants $<32$ weeks gestational age: Matched cohort study of neonatal outcomes. J. Perinatol. 2009, 29, 693-697.

2. Shah, P.K.; Narendran, V.; Kalpana, N. Aggressive posterior retinopathy of prematurity in large preterm babies in South India. Arch. Dis. Child. Fetal Neonatal Ed. 2012, 97, F371-F375. [CrossRef] [PubMed]

3. Wyckoff, M.H.; Perlman, J.M. Cardiopulmonary resuscitation in very low birth weight infants. Pediatrics 2000, 106, 618-620. [CrossRef] [PubMed]

4. Wyckoff, M.H.; Salhab, W.A.; Heyne, R.J.; Kendrick, D.E.; Stoll, B.; Laptook, A.R.; National Institute of Child Health and Human Development Neonatal Research Network. Outcome of extremely low birth weight infants who received delivery room cardiopulmonary resuscitation. J. Pediatr. 2012, 160, 239-244.e2. [CrossRef] [PubMed]

5. Soraisham, A.S.; Lodha, A.K.; Singhal, N.; Aziz, K.; Yang, J.; Lee, S.K.; Shah, P.S. On behalf of the Canadian Neonatal Network. Neonatal outcomes following extensive cardiopulmonary resuscitation in the delivery room for infants born at less than 33 weeks gestational age. Resuscitation 2014, 85, 238-243. [CrossRef]

6. Foglia, E.E.; Weiner, G.; de Almeida, M.F.B.; Wyllie, J.P.; Wyckoff, M.H.; Rabi, Y.; Guinsburg, R.; International Liaison Committee on Resuscitation Neonatal Life Support Task Force. Duration of Resuscitation at Birth, Mortality, and Neurodevelopment: A Systematic Review. Pediatrics 2020, 146, e20201449. [CrossRef]

7. Harrington, D.J.; Redman, C.W.; Redman, C.W.; Moulden, M.; Greenwood, C.E. The long-term outcome in surviving infants with Apgar zero at 10 minutes: A systematic review of the literature and hospital-based cohort. Am. J. Obstet. Gynecol. 2007, 196, 463.e1-463.e5. [CrossRef]

8. Wyckoff, M.H.; Wyllie, J.P.; Aziz, K.; de Almeida, M.F.; Fabres, J.; Fawke, J.; Guinsburg, R.; Hosono, S.; Isayama, T.; Kapadia, V.S.; et al. Neonatal Life Support: 2020 International Consensus on Cardiopulmonary Resuscitation and Emergency Cardiovascular Care Science with Treatment Recommendations. Circulation 2020, 142, S185-S221. [CrossRef]

9. Aziz, K.; Lee, H.C.; Escobedo, M.B.; Hoover, A.V.; Kamath-Rayne, B.D.; Kapadia, V.S.; Magid, D.J.; Niermeyer, S.; Schmölzer, G.M.; Szyld, E.G.; et al. Part 5: Neonatal Resuscitation: 2020 American Heart Association Guidelines for Cardiopulmonary Resuscitation and Emergency Cardiovascular Care. Circulation 2020, 142, S524-S550. [CrossRef]

10. Solevåg, A.; Dannevig, I.; Wyckoff, M.H.; Saugstad, O.D.; Nakstad, B. Extended series of cardiac compressions during CPR in a swine model of perinatal asphyxia. Resuscitation 2010, 81, 1571-1576. [CrossRef]

11. Solevåg, A.; Dannevig, I.; Wyckoff, M.H.; Saugstad, O.D.; Nakstad, B. Return of spontaneous circulation with a compression:ventilation ratio of 15:2 versus 3:1 in newborn pigs with cardiac arrest due to asphyxia. Arch. Dis. Child. Fetal Neonatal Ed. 2011, 96, F417-F421. [CrossRef] [PubMed] 
12. Solevåg, A.; Schmölzer, G.M.; O’Reilly, M.; Lu, M.; Lee, T.-F.; Hornberger, L.K.; Nakstad, B.; Cheung, P.-Y. Myocardial perfusion and oxidative stress after $21 \%$ vs. $100 \%$ oxygen ventilation and uninterrupted chest compressions in severely asphyxiated piglets. Resuscitation 2016, 106, 7-13. [CrossRef] [PubMed]

13. Schmölzer, G.M.; O’Reilly, M.; LaBossiere, J.; Lee, T.-F.; Cowan, S.; Nicoll, J.; Bigam, D.L.; Cheung, P.-Y. 3:1 compression to ventilation ratio versus continuous chest compression with asynchronous ventilation in a porcine model of neonatal resuscitation. Resuscitation 2014, 85, 270-275. [CrossRef] [PubMed]

14. Pasquin, M.P.; Cheung, P.-Y.; Patel, S.; Lu, M.; Lee, T.-F.; Wagner, M.; O’Reilly, M.; Schmölzer, G.M. Comparison of Different Compression to Ventilation Ratios (2: 1, 3: 1, and 4: 1) during Cardiopulmonary Resuscitation in a Porcine Model of Neonatal Asphyxia. Neonatology 2018, 114, 37-45. [CrossRef] [PubMed]

15. Schmölzer, G.M.; O’Reilly, M.; LaBossiere, J.; Lee, T.-F.; Cowan, S.; Qin, S.; Bigam, D.L.; Cheung, P.-Y. Cardiopulmonary resuscitation with chest compressions during sustained inflations: A new technique of neonatal resuscitation that improves recovery and survival in a neonatal porcine model. Circulation 2013, 128, 2495-2503. [CrossRef]

16. Berg, R.A.; Kern, K.B.; Sanders, A.B.; Otto, C.W.; Hilwig, R.W.; Ewy, G.A. Bystander cardiopulmonary resuscitation. Is ventilation necessary? Circulation 1993, 88, 1907-1915. [CrossRef]

17. Berg, R.A.; Hilwig, R.W.; Kern, K.B.; Ewy, G.A. "Bystander" Chest Compressions and Assisted Ventilation Independently Improve Outcome From Piglet Asphyxial Pulseless "Cardiac Arrest". Circulation 2000, 101, 1743-1748. [CrossRef]

18. Berg, R.A.; Hilwig, R.W.; Kern, K.B.; Barbar, I.; Ewy, G.A. Simulated mouth-to-mouth ventilation and chest compressions (bystander cardiopulmonary resuscitation) improves outcome in a swine model of prehospital pediatric asphyxial cardiac arrest. Crit. Care Med. 1999, 27, 1893-1899. [CrossRef]

19. Boldingh, A.M.; Solevåg, A.; Aasen, E.; Nakstad, B. Resuscitators who compared four simulated infant cardiopulmonary resuscitation methods favoured the three-to-one compression-to-ventilation ratio. Acta Paediatr. 2016, 105, 910-916. [CrossRef]

20. Schmölzer, G.M.; Bhatia, R.; Davis, P.G.; Tingay, D.G. A comparison of different bedside techniques to determine endotracheal tube position in a neonatal piglet model. Pediatr. Pulmonol. 2013, 48, 138-145. [CrossRef]

21. Mustofa, J.; Cheung, P.-Y.; Patel, S.; Lee, T.-F.; Lu, M.; Pasquin, M.P.; O’Reilly, M.; Schmölzer, G.M. Effects of different durations of sustained inflation during cardiopulmonary resuscitation on return of spontaneous circulation and hemodynamic recovery in severely asphyxiated piglets. Resuscitation 2018, 129, 82-89. [PubMed]

22. Shim, G.-H.; Kim, S.Y.; Cheung, P.-Y.; Lee, T.-F.; O’Reilly, M.; Schmölzer, G.M. Effects of sustained inflation pressure during neonatal cardiopulmonary resuscitation of asphyxiated piglets. PLoS ONE 2020, 15, e228693. [CrossRef] [PubMed]

23. La Garde, R.P.; Cheung, P.-Y.; Yaskina, M.; Lee, T.-F.; O’Reilly, M.; Schmölzer, G.M. Sex Differences Between Female and Male Newborn Piglets During Asphyxia, Resuscitation, and Recovery. Front. Pediatr. 2019, 7. [CrossRef] [PubMed]

24. Kim, S.Y.; Shim, G.-H.; O’Reilly, M.; Cheung, P.-Y.; Lee, T.-F.; Schmölzer, G.M. Asphyxiated Female and Male Newborn Piglets Have Similar Outcomes with Different Cardiopulmonary Resuscitation Interventions. Front. Pediatr. 2020, 8. [CrossRef]

25. Rudikoff, M.; Maughan, W.L.; Effron, M.; Fresson, J.; Weisfeldt, M.L. Mechanisms of blood flow during cardiopulmonary resuscitation. Circulation 1980, 61, 345-352. [CrossRef]

26. Chandra, N.; Weisfeldt, M.L.; Tsitlik, J.; Vaghaiwalla, F.; Snyder, L.D.; Hoffecker, M.; Rudikoff, M. Augmentation of carotid flow during cardiopulmonary resuscitation by ventilation at high airway pressure simultaneous with chest compression. Am. J. Cardiol. 1981, 48, 1053-1063. [CrossRef]

27. Chandra, N.; Rudikoff, M.; Weisfeldt, M.L. Simultaneous chest compression and ventilation at high airway pressure during cardiopulmonary resuscitation. Lancet 1980, 315, 175-178. [CrossRef]

28. Koehler, R.C.; Tsitlik, J.; Chandra, N.; Guerci, A.D.; Rogers, M.C.; Weisfeldt, M.L. Augmentation of cerebral perfusion by simultaneous chest compression and lung inflation with abdominal binding after cardiac arrest in dogs. Circulation 1983, 67, 266-275. [CrossRef]

29. Berkowitz, I.D.; Chantarojanasiri, T.; Koehler, R.C.; Schleien, C.L.; Dean, J.M.; Michael, J.R.; Rogers, M.C.; Traystman, R.J. Blood Flow during Cardiopulmonary Resuscitation with Simultaneous Compression and Ventilation in Infant Pigs. Pediatr. Res. 1989, 26, 558-559. [CrossRef]

30. Sobotka, K.; Hooper, S.B.; Allison, B.J.; Davis, P.G.; Morley, C.J.; Moss, T.J.M. An initial sustained inflation improves the respiratory and cardiovascular transition at birth in preterm lambs. Pediatr. Res. 2011, 70, 56-60. [CrossRef]

31. Vali, P.; Chandrasekharan, P.K.; Rawat, M.; Gugino, S.F.; Koenigsknecht, C.; Helman, J.; Mathew, B.; Berkelhamer, S.; Nair, J.; Lakshminrusimha, S. Continuous Chest Compressions During Sustained Inflations in a Perinatal Asphyxial Cardiac Arrest Lamb Model. Pediatr. Crit. Care Med. 2017, 18, e370-e377. [CrossRef] [PubMed]

32. Li, E.S.; Görens, I.; Cheung, P.Y.; Lee, T.F.; Lu, M.; O’Reilly, M.; Schmölzer, G.M. Chest Compressions during Sustained Inflations Improve Recovery When Compared to a 3:1 Compression:Ventilation Ratio during Cardiopulmonary Resuscitation in a Neonatal Porcine Model of Asphyxia. Neonatology 2017, 112, 337-346. [CrossRef] [PubMed]

33. Babbs, C.; Meyer, A.; Nadkarni, V. Neonatal CPR: Room at the top-A mathematical study of optimal chest compression frequency versus body size. Resuscitation 2009, 80, 1280-1284. [CrossRef] [PubMed]

34. Solevåg, A.; Cheung, P.-Y.; Li, E.S.-S.; Xue, S.Z.; O’Reilly, M.; Fu, B.; Zheng, B.; Schmölzer, G.M. Chest Compression Quality in a Newborn Manikin: A Randomized Crossover Trial (August 2016). IEEE J. Transl. Eng. Health Med. 2018, 6, 1-5. [CrossRef]

35. Enriquez, D.; Meritano, J.; Shah, B.A.; Song, C.; Szyld, E. Fatigue during Chest Compression Using a Neonatal Patient Simulator. Amer. J. Perinatol. 2018, 35, 796-800. [CrossRef] 
36. Haque, I.U.; Udassi, J.P.; Udassi, S.; Theriaque, D.W.; Shuster, J.J.; Zaritsky, A.L. Chest compression quality and rescuer fatigue with increased compression to ventilation ratio during single rescuer pediatric CPR. Resuscitation 2008, 79, 82-89. [CrossRef]

37. Te Pas, A.B.; Davis, P.G.; Hooper, S.B.; Morley, C.J. From liquid to air: Breathing after birth. J. Pediatr. 2008, 152, 607-611. [CrossRef]

38. Hooper, S.B.; Te Pas, A.B.; Kitchen, M. Respiratory transition in the newborn: A three-phase process. Arch. Dis. Child. Fetal Neonatal Ed. 2016, 101, F266-F271.

39. Solevåg, A.; Lee, T.-F.; Lu, M.; Schmölzer, G.M.; Cheung, P.-Y. Tidal volume delivery during continuous chest compressions and sustained inflation. Arch. Dis. Child. Fetal Neonatal Ed. 2017, 102, F85-F87. [CrossRef]

40. Tsui, B.C.H.; Horne, S.; Tsui, J.; Corry, G.N. Generation of tidal volume via gentle chest pressure in children over one year old. Resuscitation 2015, 92, 148-153. [CrossRef]

41. Schmölzer, G.M.; O’Reilly, M.; Fray, C.; van Os, S.; Cheung, P.-Y. Chest compression during sustained inflation versus 3:1 chest compression:ventilation ratio during neonatal cardiopulmonary resuscitation: A randomised feasibility trial. Arch. Dis. Child. Fetal Neonatal Ed. 2018, 103, F455-F460. [CrossRef] [PubMed]

42. Li, E.S.-S.; Cheung, P.-Y.; O'Reilly, M.; Schmölzer, G.M. Change in tidal volume during cardiopulmonary resuscitation in newborn piglets. Arch. Dis. Child. Fetal Neonatal Ed. 2015, 100, F530-F533. [CrossRef] [PubMed]

43. Li, E.S.-S.; Cheung, P.-Y.; Pichler, G.; Aziz, K.; Schmölzer, G.M. Respiratory function and near infrared spectroscopy recording during cardiopulmonary resuscitation in an extremely preterm newborn. Neonatology 2014, 105, 200-204. [CrossRef]

44. Foglia, E.E.; Te Pas, A.B. Sustained Lung Inflation: Physiology and Practice. Clin. Perinatol. 2016, 43, 633-646. [CrossRef] [PubMed]

45. Foglia, E.E.; Te Pas, A.B.; Kirpalani, H.M.; Davis, P.G.; Owen, L.; van Kaam, A.H.; Onland, W.; Keszler, M.; Schmölzer, G.M.; Hummler, H.D.; et al. Sustained Inflation vs Standard Resuscitation for Preterm Infants. JAMA Pediatr. 2020, 174. [CrossRef]

46. Kapadia, V.S.; Urlesberger, B.; Soraisham, A.S.; Liley, H.G.; Schmölzer, G.M.; Rabi, Y.; Wyllie, J.P.; Wyckoff, M.H. On behalf of the International Liaison Committee on Resuscitation Neonatal Life Support Task Force. Sustained Lung Inflations During Neonatal Resuscitation at Birth: A Meta-analysis. Pediatrics 2021, 147. [CrossRef]

47. Wyllie, J.P.; Bruinenberg, J.; Roehr, C.-C.; Rüdiger, M.; Trevisanuto, D.; Urlesberger, B. European Resuscitation Council Guidelines for Resuscitation 2015: Section 7. Resuscitation and support of transition of babies at birth. Resuscitation 2015, 95, 249-263. [CrossRef]

48. Klingenberg, C.; Sobotka, K.; Ong, T.; Allison, B.J.; Schmölzer, G.M.; Moss, T.J.M.; Polglase, G.R.; Dawson, J.A.; Davis, P.G.; Hooper, S.B. Effect of sustained inflation duration; resuscitation of near-term asphyxiated lambs. Arch. Dis. Child. Fetal Neonatal Ed. 2013, 98, F222-F227. [CrossRef]

49. Garcia-Hidalgo, C.; Cheung, P.-Y.; Vento, M.; O’Reilly, M.; Schmölzer, G.M. A Review of Oxygen Use During Chest Compressions in Newborns-A Meta-Analysis of Animal Data. Front. Pediatr. 2018, 6, 400. [CrossRef]

50. Garcia-Hidalgo, C.; Solevåg, A.; Kim, S.Y.; Shim, G.-H.; Cheung, P.-Y.; Lee, T.-F.; O’Reilly, M.; Schmölzer, G.M. Sustained inflation with $21 \%$ versus $100 \%$ oxygen during cardiopulmonary resuscitation of asphyxiated newborn piglets-A randomized controlled animal study. Resuscitation 2020, 155, 39-47. [CrossRef]

51. Perlman, J.M.; Wyllie, J.P.; Kattwinkel, J.; Wyckoff, M.H.; Aziz, K.; Guinsburg, R.; Kim, H.-S.; Liley, H.G.; Mildenhall, L.F.J.; Simon, W.M.; et al. Neonatal Resuscitation Chapter Collaborators Part 7: Neonatal Resuscitation: 2015 International Consensus on Cardiopulmonary Resuscitation and Emergency Cardiovascular Care Science with Treatment Recommendations (Reprint). Pediatrics 2015, 136, S120-S166. [CrossRef] [PubMed]

52. Wyckoff, M.H.; Aziz, K.; Escobedo, M.B.; Kapadia, V.S.; Kattwinkel, J.; Perlman, J.M.; Simon, W.M.; Weiner, G.M.; Zaichkin, J.G. Part 13: Neonatal Resuscitation: 2015 American Heart Association Guidelines Update for Cardiopulmonary Resuscitation and Emergency Cardiovascular Care (Reprint). Pediatrics 2015, 136, S196-S218. [CrossRef] [PubMed]

53. Luong, D.H.; Cheung, P.-Y.; Barrington, K.J.; Davis, P.G.; Unrau, J.; Dakshinamurti, S.; Schmölzer, G.M. Cardiac arrest with pulseless electrical activity rhythm in newborn infants: A case series. Arch. Dis. Child. Fetal Neonatal Ed. 2019, 104, F572-F574. [CrossRef] [PubMed]

54. Sillers, L.; Handley, S.C.; James, J.R. Pulseless Electrical Activity Complicating Neonatal Resuscitation. Neonatology 2018, 115, 95-98. [CrossRef] [PubMed]

55. Patel, S.; Cheung, P.-Y.; Solevåg, A.; Barrington, K.J.; Kamlin, C.O.F.; Davis, P.G.; Schmölzer, G.M. Pulseless electrical activity: A misdiagnosed entity during asphyxia in newborn infants? Arch. Dis. Child. Fetal Neonatal Ed. 2019, 104, F215-F217. [CrossRef] [PubMed]

56. Solevåg, A.L.; Luong, D.; Lee, T.F.; O’Reilly, M.; Cheung, P.Y.; Schmölzer, G.M. Non-perfusing cardiac rhythms in asphyxiated newborn piglets. PLOS ONE 2019, 14. [CrossRef]

57. Luong, D.H.; Cheung, P.-Y.; O’Reilly, M.; Lee, T.-F.; Schmölzer, G.M. Electrocardiography vs. Auscultation to Assess Heart Rate During Cardiac Arrest with Pulseless Electrical Activity in Newborn Infants. Front. Pediatr. 2018, 6, 366. [CrossRef] [PubMed]

58. Lista, G.; Boni, L.; Scopesi, F.; Mosca, F.; Trevisanuto, D.; Messner, H.; Vento, G.; Magaldi, R.; Del Vecchio, A.; Agosti, M.; et al. SLI Trial Investigators Sustained lung inflation at birth for preterm infants: A randomized clinical trial. Pediatrics 2015, 135, e457-e464. [CrossRef] 
59. Polglase, G.R.; Miller, S.L.; Barton, S.K.; Baburamani, A.A.; Wong, F.Y.; Aridas, J.D.S.; Gill, A.W.; Moss, T.J.M.; Tolcos, M.; Kluckow, M.; et al. Initiation of resuscitation with high tidal volumes causes cerebral hemodynamic disturbance, brain inflammation and injury in preterm lambs. PLoS ONE 2012, 7, e39535. [CrossRef]

60. La Verde, A.; Franchini, S.; Lapergola, G.; Lista, G.; Barbagallo, I.; Livolti, G.; Gazzolo, D. Effects of Sustained Inflation or Positive Pressure Ventilation on the Release of Adrenomedullin in Preterm Infants with Respiratory Failure at Birth. Amer. J. Perinatol. 2019, 36, S110-S114. [CrossRef]

61. Harling, A.E.; Beresford, M.W.; Vince, G.S.; Bates, M.; Yoxall, C.W. Does sustained lung inflation at resuscitation reduce lung injury in the preterm infant? Arch. Dis. Child. Fetal Neonatal Ed. 2005, 90, F406-F410. [CrossRef] [PubMed]

62. Sobotka, K.; Hooper, S.B.; Crossley, K.J.; Ong, T.; Schmölzer, G.M.; Barton, S.K.; McDougall, A.R.A.; Miller, S.L.; Tolcos, M.; Klingenberg, C.; et al. Single Sustained Inflation followed by Ventilation Leads to Rapid Cardiorespiratory Recovery but Causes Cerebral Vascular Leakage in Asphyxiated Near-Term Lambs. PLoS ONE 2016, 11, e0146574.

63. Schmölzer, G.M. Chest Compressions During Sustained Inflation During Cardiopulmonary Resuscitation in Newborn Infants Translating Evidence From Animal \& Bench Studies to the Bedside. JACC Basic Transl. Sci. 2019, 4, 116-121. [PubMed]

64. Schmölzer, G.M.; Pichler, G.; Solevåg, A.; Fray, C.; van Os, S.; Cheung, P.-Y. The SURV1VE trial—Sustained inflation and chest compression versus 3:1 chest compression-to-ventilation ratio during cardiopulmonary resuscitation of asphyxiated newborns: Study protocol for a cluster randomized controlled trial. Trials 2019, 20, 39. [CrossRef] [PubMed]

65. Aziz, K.; Chadwick, M.; Baker, M.; Andrews, W. Ante- and intra-partum factors that predict increased need for neonatal resuscitation. Resuscitation 2008, 79, 444-452. [CrossRef]

66. Schmölzer, G.M.; Kumar, M.; Aziz, K.; Pichler, G.; O’Reilly, M.; Lista, G.; Cheung, P.Y. Sustained inflation versus positive pressure ventilation at birth: A systematic review and meta-analysis. Arch. Dis. Child. Fetal Neonatal Ed. 2015, 100, F361-F368. [CrossRef]

67. Kirpalani, H.M.; Ratcliffe, S.J.; Keszler, M.; Davis, P.G.; Foglia, E.E.; Te Pas, A.B.; Fernando, M.; Chaudhary, A.; Localio, R.; van Kaam, A.H.; et al. Effect of Sustained Inflations vs Intermittent Positive Pressure Ventilation on Bronchopulmonary Dysplasia or Death Among Extremely Preterm Infants. JAMA 2019, 321, 1165-1175. [CrossRef] 